\title{
Reproduction of a Reversed Boiled Egg (the Yolk Inside Out) Listed in an Old Japanese Recipe Book
}

\author{
Hajime Hatta $^{1,}$, Ayami Nakamoto ${ }^{1}$, Yasumi Horimoto ${ }^{2}$ \\ ${ }^{1}$ Department of Food and Nutrition, Faculty of Home Economics, Kyoto Women’s University, Kyoto 605-8501, Japan. \\ ${ }^{2}$ Department of Food Science University of Guelph, Guelph, ON, N1G 2W1, Canada.
}

\begin{abstract}
How to cite this paper: Hajime Hatta, Ayami Nakamoto, Yasumi Horimoto. (2021) Reproduction of a Reversed Boiled Egg (the Yolk Inside Out) Listed in an Old Japanese Recipe Book. International Journal of Food Science and Agriculture, 5(2), 293-302.

DOI: $10.26855 /$ ijfsa.2021.06.013
\end{abstract}

Received: April 12, 2021

Accepted: May 8, 2021

Published: May 26, 2021

*Corresponding author: Hajime Hatta, Department of Food and Nutrition, Faculty of Home Economics, Kyoto Women's University, Kyoto 605-8501, Japan.

Email: hatta@kyoto-wu.ac.jp

\begin{abstract}
A method for preparing a reversed boiled egg introduced in an old Japanese recipe book has been a mystery for a long time until we recently succeeded in reproducing it 220 years later. The recipe book was published in 1785, in which 103 recipes for cooking eggs were introduced. Although 102 recipes have been recreated, only the reversed boiled egg failed to be reproduced, despite numerous challenges had been carried out. The recipe book reads, "Prepare a fresh egg and pierce the eggshell by about $3 \mathrm{~cm}$ depth with a needle. Leave it in fermented, salted rice-bran paste for three days, and then boil the egg to ensure the yolk inside out”. The key to solving the mystery lay in the idea that the eggs used for cooking in such an old period could be mostly fertilized eggs. We finally reproduced the reversed boiled egg by using fertilized eggs incubated for three days at $38^{\circ} \mathrm{C}$. The objective of this study is to reveal the cooking principle of a reversed boiled egg. Fertilized and unfertilized eggs were incubated for seven days at $38^{\circ} \mathrm{C}$ with a relative humidity of $70 \%$ (hatching condition). The changes in fertilized and unfertilized eggs (such as a ratio of egg yolk and egg white, water content, $\mathrm{pH}$, yolk viscosity, and gelation temperature by heat treatment) were compared. For 3-4 days incubation of fertilized eggs, water in the egg white is transferred to the egg yolk. As a result, the weight of the egg yolk doubled, and the viscosity of the egg yolk significantly decreased by one hundredth, becoming watery. On the other hand, the egg white weight halved, and it got thick. During this process, the vitelline membrane became very weak and easy to be broken. Upon being ruptured the membrane, the runny yolk diffused inside the eggshell, and the watery yolk gelled outside the thick egg white during heated. Thus, the reversed boiled egg (the Yolk Inside Out) was reproduced.
\end{abstract}

\section{Keywords}

Reversed Boiled Egg, Fertilized Egg, Heat Gelation, Viscosity, Dynamic Viscoelasticity

\section{Introduction}

A recipe for a reversed boiled egg, the yolk inside out, was introduced in an old Japanese cookbook called "Manpou Ryori Himitsu Bako (A Treasure of Secret Recipes)” published in 1785 (Figure 1). The recipe of a reversed boiled egg was described as follows, "Prepare a fresh egg and pierce the eggshell by about $3 \mathrm{~cm}$ depth from the blunt end of the egg with a needle. Leave it in fermented, salted rice-bran paste (Nuka-miso in Japanese) for three days, and then boil the egg to ensure the yolk inside out, resulting in a reversed boiled egg”.

The egg cookbook includes 103 egg recipes. Of all the recipes in the book, only the reversed boiled egg has never been reproduced. We presumed that "a fresh egg" in old Japan could be a freshly laid fertilized egg. For the first time in 220 years, we successfully recreated the recipe of "a reversed boiled egg" using a fertilized egg at 3-4 days incubation 
in hatching condition.

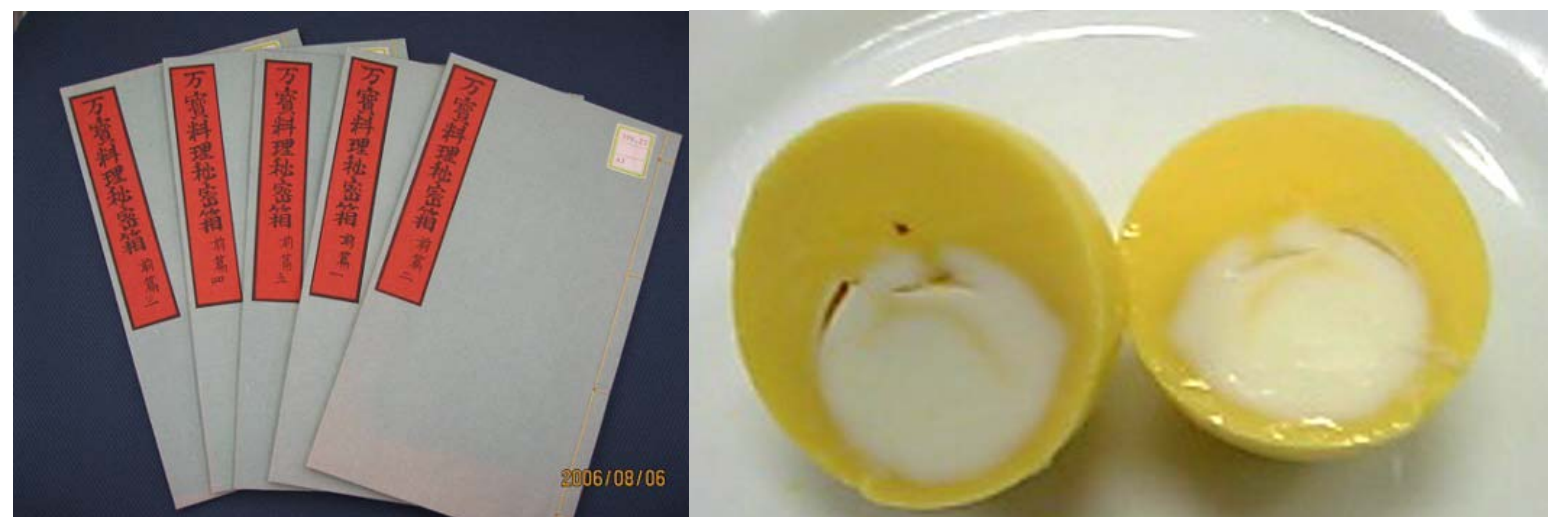

Figure 1. Manpou Ryori Himitsu Bako (A Treasure of Secret Recipes) published in 1785 and a recreated reversed boiled egg (yolk inside out).

Why was it that a reversed boiled egg could not be reproduced using an unfertilized egg, but a reversed boiled egg can be reproduced using a fertilized egg? To elucidate the preparation principle of a reversed boiled egg, the present study investigated the changes of fertilized and unfertilized eggs during incubation at $38^{\circ} \mathrm{C}$ with $\mathrm{RH} 70 \%$. Compositional ratio (egg yolk/egg white/eggshell), water content, $\mathrm{pH}$, yolk viscosity, and dynamic viscoelasticity of fertilized and unfertilized eggs were determined and compared.

\section{Methods}

\subsection{Materials}

Fertilized eggs from White Leghorn chickens were purchased from Mie Chick Co., Ltd. (Mie, Japan). Eggs were collected upon being laid and stored at $18^{\circ} \mathrm{C}$ for $1-2$ days. Then eggs were transported in a day to our laboratory at room temperature. Unfertilized eggs from Rhode Island Red chickens were purchased upon being laid from a local poultry farm (Toritomo Yokei, Kyoto, Japan). All chemicals and reagents were of analytical grades.

\subsection{Sample preparation}

\subsubsection{Incubation conditions and preparation of shelled eggs}

Fertilized and unfertilized eggs were received around noon. These were immediately incubated in an automatic egg rotating incubator $\left(38^{\circ} \mathrm{C}, \mathrm{RH} 70 \%\right)$ for 7 days. During incubation, eggs were removed daily from the incubator around noon to measure the weight of eggs. Then, eggshell, egg white, and egg yolk were separated, and each weight was measured. The incubated fertilized and unfertilized eggs were used to prepare a boiled egg.

\subsubsection{Preparation of egg white and egg yolk}

After the weight of unfertilized eggs was measured, the egg yolk and egg white were separated using an egg yolk separator. The egg yolk was rolled on filter paper to remove extra egg white on the vitelline membrane. To collect the egg yolk, a disposable syringe $(10 \mathrm{~mL})$ without a needle was then inserted into the vitelline membrane without being contaminated by the egg white. This became an egg yolk sample of an unfertilized egg. The separated egg white was placed on a stainless-steel colander (15 cm diameter, ten mesh sieve) to separate the thin egg white from the thick one. The weights of both thin and thick egg whites were measured. Then both egg whites were remixed to be homogenous. This became an egg white sample in an unfertilized egg. Sodium azide $0.03 \%(w / w)$ was added to samples. All samples were stored in a refrigerator until analysis.

Because the vitelline membrane of a fertilized egg after 3 days incubation becomes easily broken as hatching progresses, we devised a protocol for cracking shelled eggs in saline to collect samples. A stainless-steel bowl $(15 \mathrm{~cm}$ diameter) and a stainless-steel colander (10 mesh sieve) were stacked together and filled with $300 \mathrm{ml}$ of saline. After weighing the fertilized egg, the egg was cracked carefully in the saline solution. The thin egg white was dispersed into the saline, and its weight was calculated by the gained weight on the saline after the stainless-steel colander was lifted carefully to recover the egg yolk, embryo, and thick egg white. These were washed by soaking in $300 \mathrm{~mL}$ of saline twice. A disposable $10 \mathrm{~mL}$ syringe (without a needle) was inserted into the vitelline membrane to collect the egg yolk. This became an egg yolk sample in a fertilized egg incubated for 3-7 days. After collecting the egg yolk, the thick egg white, embryo, and allantois on the colander were washed with $300 \mathrm{~mL}$ of saline water twice. These weights were then measured. The recovered thick egg white became an egg white sample in a fertilized egg incubated for 3-7 days. So- 
dium azide $0.03 \%(\mathrm{w} / \mathrm{w})$ was added to each sample. All samples were stored in a refrigerator until analysis.

\subsection{Reproduction of a reversed boiled egg}

Fertilized and unfertilized eggs incubated from day 0 to day 7 were taken daily from the incubator. An 18G needle (Terumo Inc., Japan) was inserted to a depth of about $3 \mathrm{~cm}$ from the blunt end of the egg. To prevent the egg content from coming out, the hole of the eggshell was shielded with an instant adhesive (Alon Alpha ${ }^{\circledR}$ ). The egg was then placed in a pot and heated while slowly being stirred to make a hard-boiled egg. After boiled for 15 minutes, the egg was soaked in cold water to cool it, carefully peeled, cut in half vertically with a knife, and photographed each boiled egg.

\subsection{Composition analysis of fertilized and unfertilized eggs}

\subsubsection{Water content and $\mathrm{pH}$ of egg white and egg yolk}

The egg yolk and egg white in fertilized and unfertilized eggs (day 0 to day 7) were used to measure the water content and $\mathrm{pH}$. An aluminium cup containing about $1 \mathrm{~g}$ of 14-20 mesh sea sand (Nacalai Tesque Inc., Japan) was baked at $105^{\circ} \mathrm{C}$ for $3 \mathrm{~h}$ and weighed using a precision balance. About $1 \mathrm{~g}$ sample was weighed precisely and mixed well with the sea sand before being baked at $105^{\circ} \mathrm{C}$ for $3 \mathrm{~h}$. The dry weight of the sample was measured. The ratio of loss on drying over sample weight was expressed as a percentage. This became the water content of each sample. For the $\mathrm{pH}$ measurement, a tiny hole was pierced at the sharp end of the egg with an $18 \mathrm{G}$ needle. A semiconductor $\mathrm{pH}$ sensor (Horiba Inc, Japan) was inserted upward slowly without breaking the vitelline membrane and the $\mathrm{pH}$ of the egg white was measured [1]. Then the egg was broken, and the $\mathrm{pH}$ of the egg yolk was measured.

\subsubsection{Viscosity of egg yolk}

BL-type Viscotester (Rion Co., Ltd., Japan) was used to measure viscosity of the egg yolk of fertilized and unfertilized eggs (from day 0 to day 7). The egg yolk samples were placed into a centrifuge tube (180 mm diameter). A rotor (No 4) was used for unfertilized eggs (day 0 to day 7) and fertilized eggs (day 0 to day 3). A rotor (No 1) was used for fertilized eggs (day 4 to day 7). The measurement was conducted at $20^{\circ} \mathrm{C}$ with $60 \mathrm{rpm}$ rotor speed.

\subsection{Dynamic viscoelasticity measurement}

Rheolograph-sol instrument (Toyo Seiki Seisakusho, Japan) was used to measure dynamic viscoelasticity of the egg yolk in fertilized and unfertilized eggs at a $5-\mathrm{Hz}$ frequency. The temperature of the sample $\left(25^{\circ} \mathrm{C}\right)$ was increased to $50^{\circ} \mathrm{C}$ in $5 \mathrm{~min}$. Then the temperature was raised to $100^{\circ} \mathrm{C}$ at a rate of $1^{\circ} \mathrm{C} / \mathrm{min}$. Storage modulus of rigidity (G': spring element) and loss modulus of rigidity (G': viscous element) were recorded from $50^{\circ} \mathrm{C}$ to $100^{\circ} \mathrm{C}$ by increments of $5^{\circ} \mathrm{C}$.

\subsection{SDS-PAGE}

Sodium dodecyl sulfate-polyacrylamide gel electrophoresis (SDS-PAGE) was performed using a mini-slab gel electrophoresis apparatus (AE-650 Rapidus, ATTO Inc., Japan). Samples used were the egg yolks of fertilized and unfertilized eggs on days $0,2,4$, and 7 and the egg whites of unfertilized eggs on day 0 . The samples were diluted with $2 \%$ SDS containing $10 \mathrm{mM}$ phosphate buffer $(\mathrm{pH} 7.2)$ to adjust the protein content $(0.1 \% \mathrm{w} / \mathrm{v})$. SDS-PAGE was run using a 12.5\% polyacrylamide gel according to the method of Laemnli [2]. The same sample was placed on two mini-slab gels and run at the same time. One gel was used for Coomassie Brilliant Blue (CBB) staining and the other was used for Western blotting.

\subsection{Western blotting and immunostaining}

A semi-dry blotting apparatus (Horizeblot: ATTO Co., Ltd., Japan) was used. After SDS-PAGE, proteins were transferred to a membrane with a continuous buffer according to the company's instruction manual. The membrane was soaked with 3\% (w/v) skim milk blocking solution overnight. The indirect enzyme labelled antibody method was used for immunoblotting. The primary antibody was anti-ovalbumin (OVA) rabbit serum (Taiyo Kagaku Co., Ltd., Japan). The secondary antibody was alkaline phosphatase (ALP) conjugated anti-rabbit IgG goat IgG. ALP activity was visualized by using an ALP assay kit (Nacalai Tesque Inc., Japan).

\section{Results}

\subsection{Changes in the composition of eggs}

The weight ratios of egg yolk, egg white, and eggshell of unfertilized eggs did not change significantly during the $38^{\circ} \mathrm{C}$ with $\mathrm{RH} 70 \%$ storage period. The weight ratios within the egg were: $20 \%$ egg yolk, $70 \%$ egg white, and $10 \%$ eggshell. The proportion of thick egg white decreased, whereas the proportion of thin egg white increased (Figure 2a). By contrast, the composition ratio of the egg yolk and egg white of fertilized eggs showed drastically change. The ratio 
of egg yolk was about $23 \%$ on day 0 . The ratio increased with increased storage days. On day 7 it accounted for about $50 \%$. The ratio of thick egg white was about $50 \%$ on day 0 , but it decreased with the increased storage days and became about $10 \%$ on day 7 . The ratio of thin egg white was about $5 \%$ on day 0 and became about $10 \%$ on day 7 . There was no change of the eggshell weight (11\%-12\%). An embryo and membrane structures (allantois) appeared on day 3 and grew gradually to account for about $10 \%$ of total egg weight on day 7 (Figure $2 b$ ).

\section{a. Unfertilized Eggs}

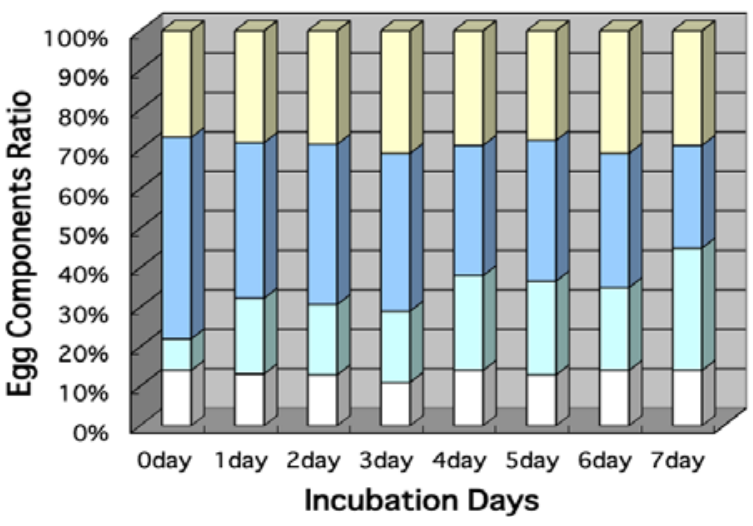

\section{b. Fertilized Eggs}

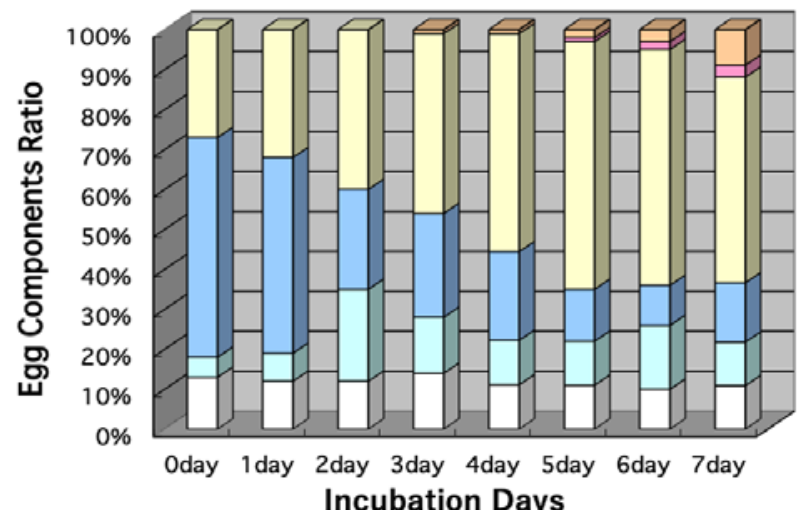

$\square$ EggShell $\square$ Thin EW $\square$ Thick EW $\square$ EY $\square$ Embryo $\square$ Allantois

Figure 2. Change in egg components ratio of fertilized and unfertilized eggs during incubation at $38^{\circ} \mathrm{C}$ with $\mathrm{RH} 70 \%$ for 7 days.

\subsection{Changes in the water content of egg white and egg yolk}

There was almost no change in the water content of the egg white in unfertilized eggs during 7 days of storage (about $88 \%$ ); however, the water content of the egg yolk increased slightly from $47.4 \%$ (day 0) to $52.1 \%$ (day 7). By contrast, the water content of both egg white and yolk in fertilized eggs changed significantly. The water content of the egg yolk in fertilized eggs was $48.1 \%$ (day 0) and increased rapidly to $72.2 \%$ (day 3), and then gradually increased to reach $76.9 \%$ on day 7 . The water content of the egg white in fertilized eggs decreased significantly from $87.6 \%$ (day 0 ) to $70.2 \%$ (day 7) (Figure 3).

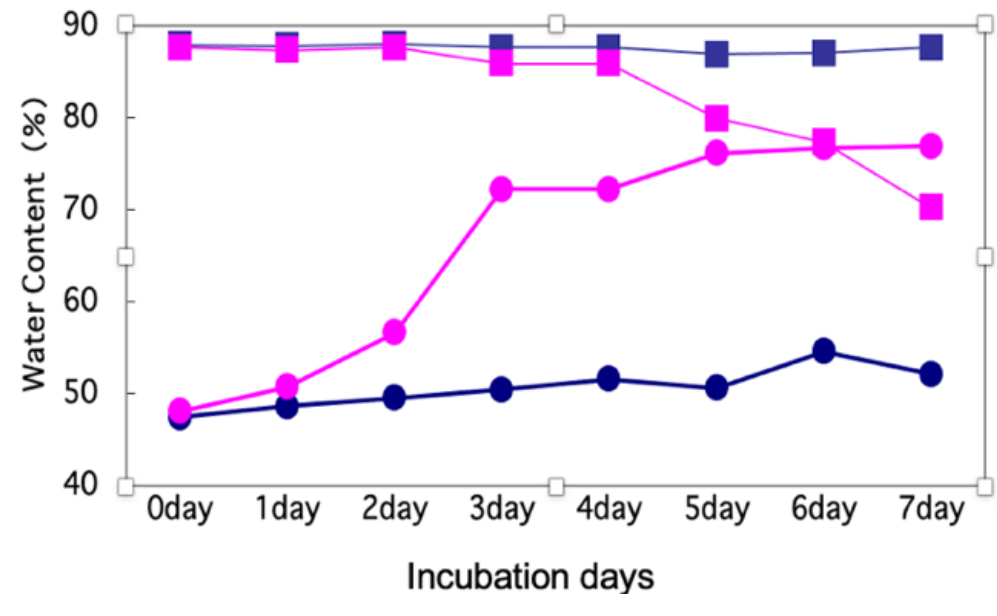

\section{Unfertilized EY - - Fertilized EY $\quad-$ - Unfertilized EW - $\quad$ - Fertilized EW}

Figure 3. Changes in $\mathrm{EY}$ and $\mathrm{EW}$ water content separated from fertilized and unfertilized eggs during incubation at $38^{\circ} \mathrm{C}$ with RH $70 \%$ for 7 days.

\subsection{Changes in Egg white and yolk pH}

The egg white $\mathrm{pH}$ of unfertilized eggs was 8.3 (day 0) and increased to 9.3 (day 1). Then it gradually increased with increased storge time and reached to 9.7 (day 7). On the other hand, the $\mathrm{pH}$ of egg white in fertilized eggs was 9.4 (day 
0), and then increased to 9.8 (day 2); however, it decreased on day 3 and dropped to 8.6 (day 7). The pH of the egg yolk in unfertilized eggs remained constant around 6.2 during the 7-day incubation. The $\mathrm{pH}$ of the yolk of fertilized eggs was around 6.2 until day 2, which was similar to that of the yolk of unfertilized eggs but started to increase from day 3 and reached 7.2 (day 6) (Figure 4).
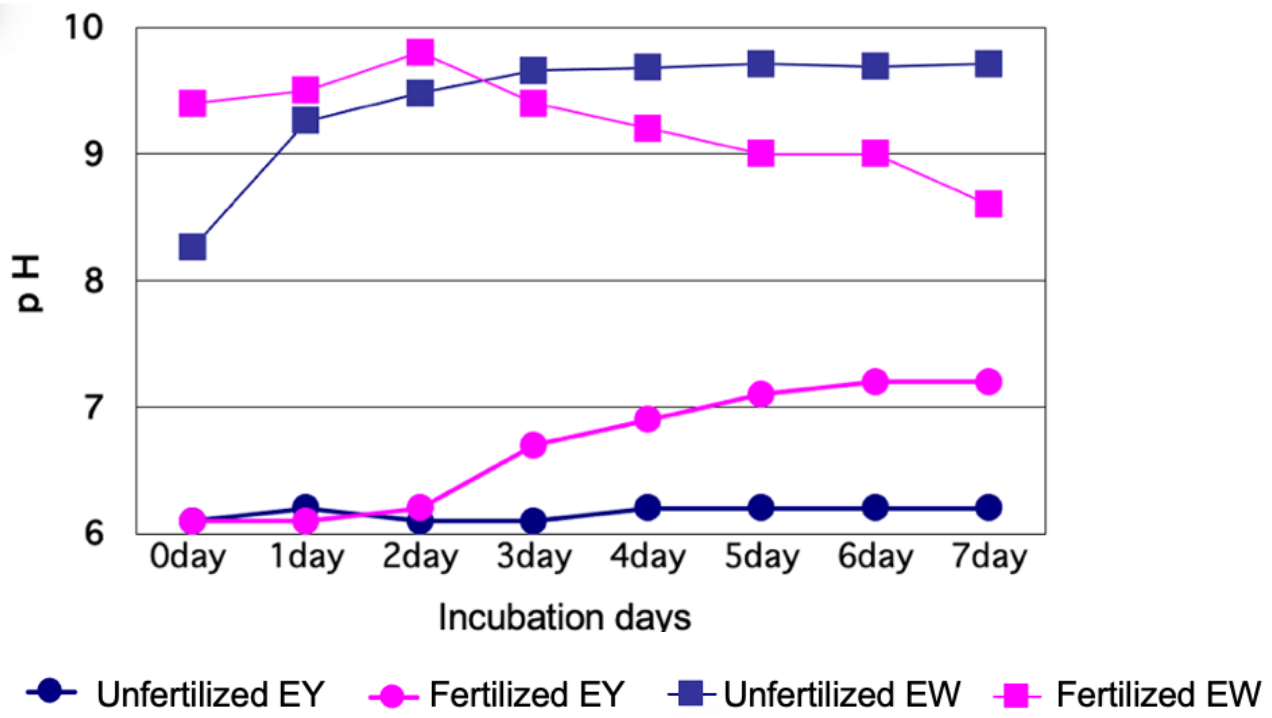

Figure 4. Changes in $\mathrm{pH}$ of EY and EW separated from fertilized and unfertilized eggs during incubation at $38^{\circ} \mathrm{C}$ with $\mathrm{RH}$ $70 \%$ for 7 days.

\subsection{Changes in viscosity of egg yolk}

The yolk viscosity of both fertilized and unfertilized eggs decreased with increased incubation time. The yolk viscosity of unfertilized eggs was 1,600cp (day 0), decreased to 850cp (day 3), and became $420 \mathrm{cp}$ (day 7). The yolk viscosity of fertilized eggs was 1,250cp (day 0), decreased linearly to 50cp (day 3) and remained below 10cp after day 4 (Figure 5).

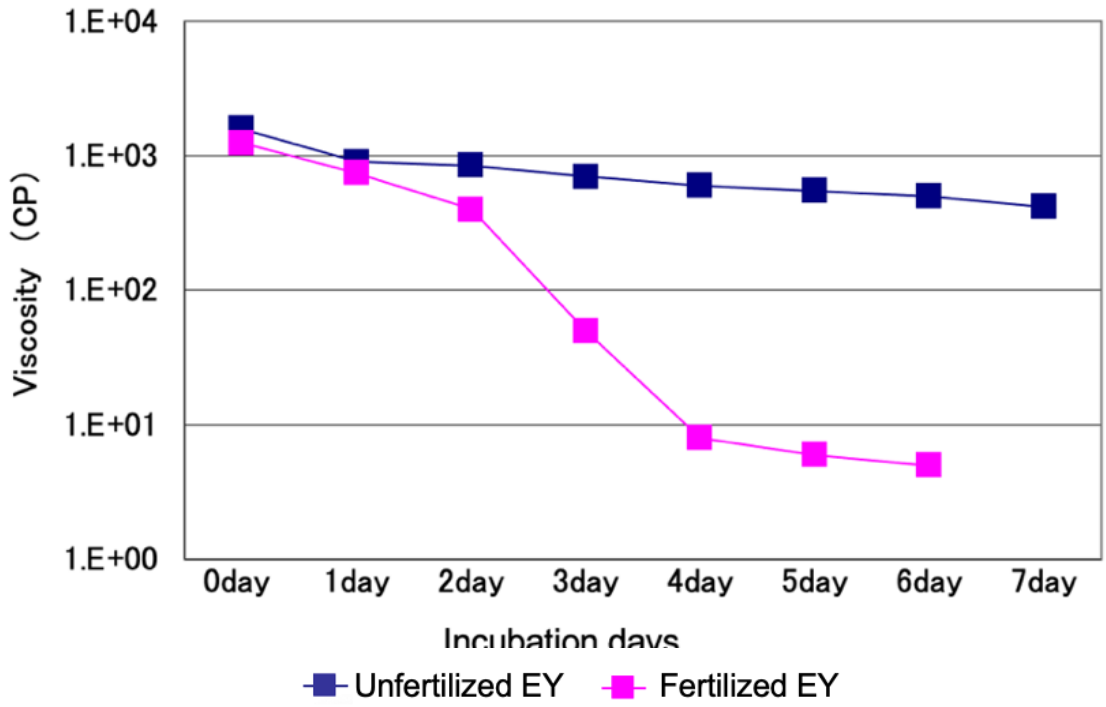

Figure 5. Change in EY viscosity separated from fertilized and unfertilized eggs during incubation at $38^{\circ} \mathrm{C}$ with $\mathrm{RH} 70 \%$ for 7 days.

\subsection{Reproduction of a reversed boiled egg}

Unfertilized eggs stored for 7 days became ordinary boiled eggs (yolk inside and egg white outside). Fertilized eggs on days 0 and 1 were ordinary boiled eggs. However, fertilized eggs on day 2 began to reverse egg yolk and white. On day 3, the egg yolk and egg white were significantly reversed, but it was incomplete. A complete reverse boiled egg 
(yolk outside and egg white inside) was obtained from a fertilized egg after day 4 (Figure 6).

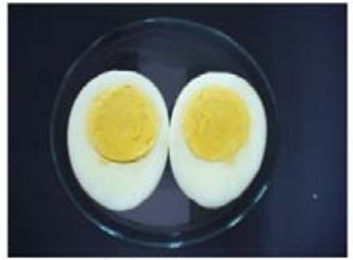

$\mathbf{0}$ day

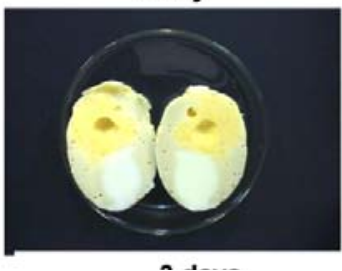

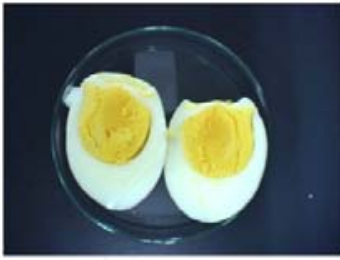

1 days

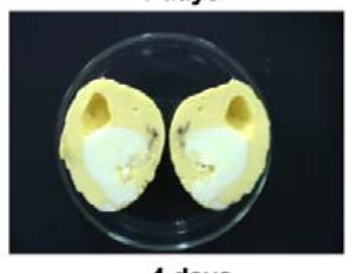

ilized

\subsection{Changes in dynamic viscoelasticity}

The dynamic viscoelasticity of the egg yolk and egg white of unfertilized and fertilized eggs was measured using a Rheolograph-SOL apparatus $\left(5 \mathrm{~Hz}\right.$, temperature increase $\left.1^{\circ} \mathrm{C} / \mathrm{min}, 50-95^{\circ} \mathrm{C}\right)$. When a rapid change in storage elastic modulus (G') was taken as the gel point [3], the yolks of unfertilized eggs (stored for 0-7 days) gelled at $65-70^{\circ} \mathrm{C}$. In addition, the egg whites of unfertilized eggs on days 0,2 , and 4 started gelling at $60^{\circ} \mathrm{C}$ and hardened at $80^{\circ} \mathrm{C}$. However, the egg whites of unfertilized eggs stored at 7 days started gelling at $70^{\circ} \mathrm{C}$ and hardened at $85^{\circ} \mathrm{C}$ (Figures $7 \mathrm{a}$ and $7 \mathrm{~b}$ ).

On the other hand, in the case of fertilized eggs, the yolk on days $0,1,2$ were gelled at $65-70^{\circ} \mathrm{C}$, similar to the yolks of unfertilized eggs. However, the gelation temperature of the yolk of the fertilized egg on day 3 shifted to the high temperature side by about $5^{\circ} \mathrm{C}$ and about $10^{\circ} \mathrm{C}$ after day 4 (Figure 7c). The egg white of fertilized eggs behaved in the same way as that of unfertilized eggs, but the egg white of fertilized eggs stored at 7 days had a storage elastic modulus (G') that shifted to a low temperature side about $5^{\circ} \mathrm{C}$ and started gelation at $55^{\circ} \mathrm{C}$ and hardened at $85^{\circ} \mathrm{C}$ (Figure $7 \mathrm{~d}$ ). In other words, as hatching progressed, the egg white became easier to be gelled.
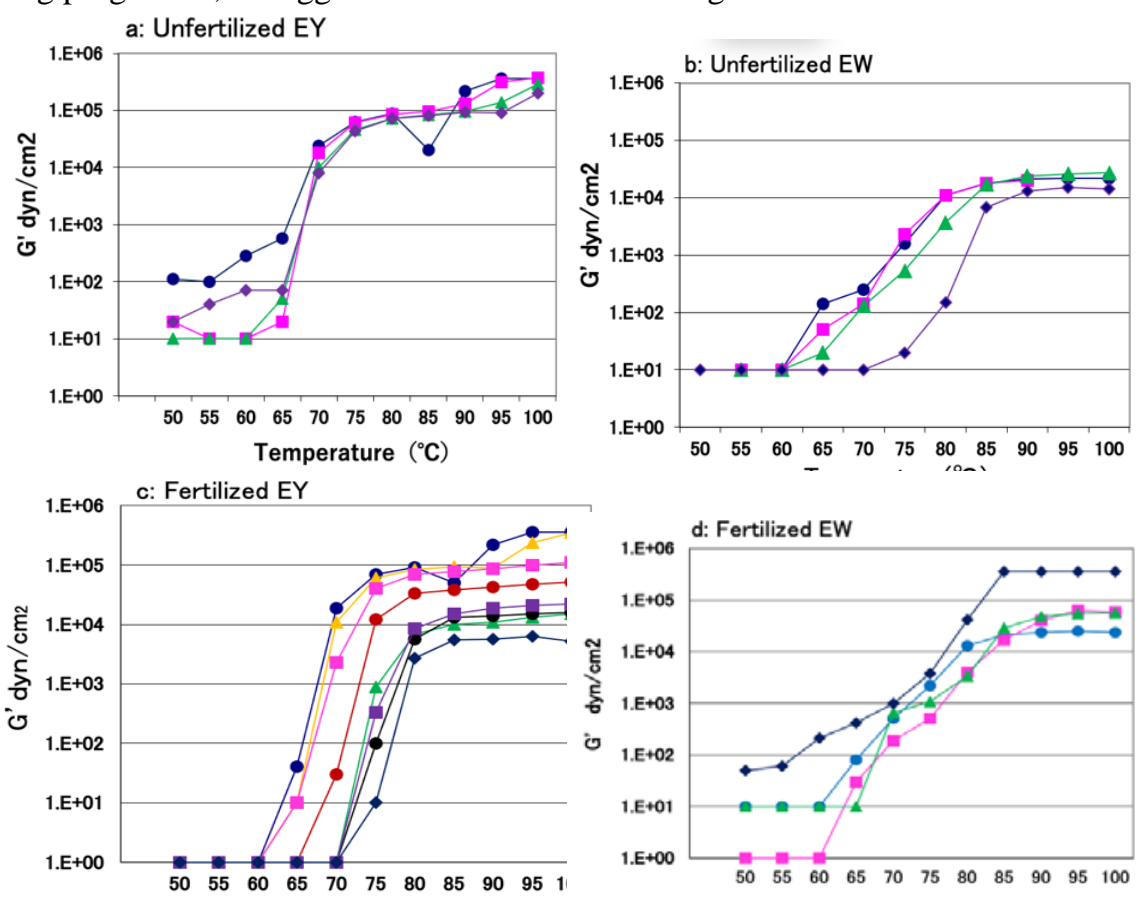

$$
-0 \text { day }-1 \text { day }-2 \text { - 2day } \rightarrow-3 \text { day } \pm \text { day } \rightarrow-5 \text { day } \rightarrow-6 \text { day } \rightarrow-7 \text { day }
$$

Figure 7. Changes in storage elastic modulus ( $\left.G^{\prime}\right)$ of EY and EW separated from fertilized and unfertilized eggs during incubation at $38^{\circ} \mathrm{C}$ with $\mathrm{RH} 70 \%$ for 7 days. 


\subsection{SDS-PAGE and Western blotting}

The egg yolk was collected carefully from fertilized and unfertilized eggs on days 0, 2, 4, and 6 without being contaminated with the egg white. The constituent proteins were analyzed by SDS-PAGE. After SDS-PAGE, Western blotting was performed to check whether egg white protein was transferred to the egg yolk, and OVA immunostaining was performed. Figure 8 shows the results of SDS-PAGE profile and Western Blotting analysis for a detection of OVA.

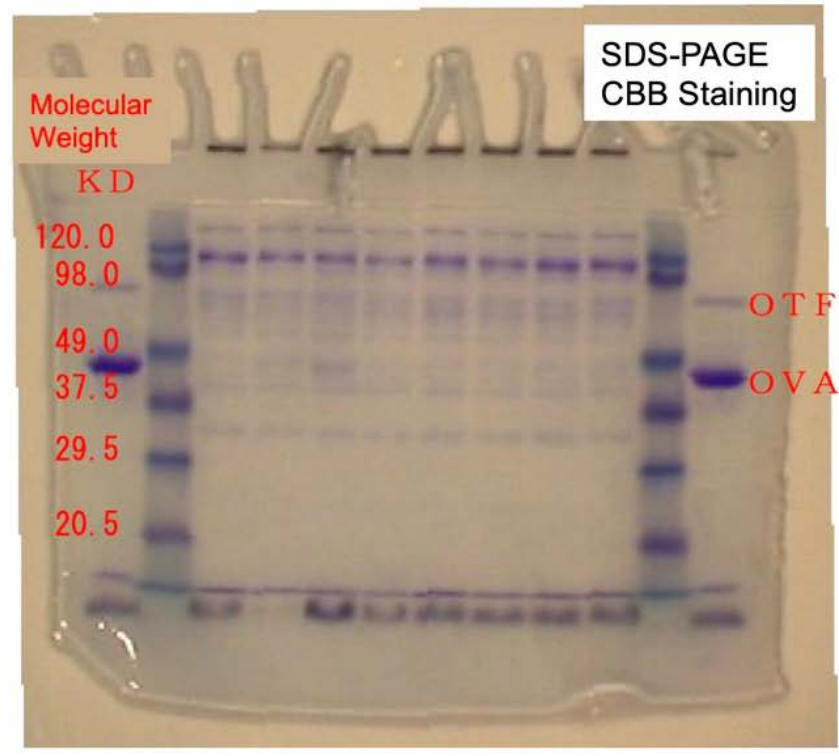

EW, MW, Fertilized, Unfertilized, MW, EW

$\begin{array}{llllllll}0 & 2 & 4 & 7 & 0 & 2 & 4 & 7\end{array}$ days days

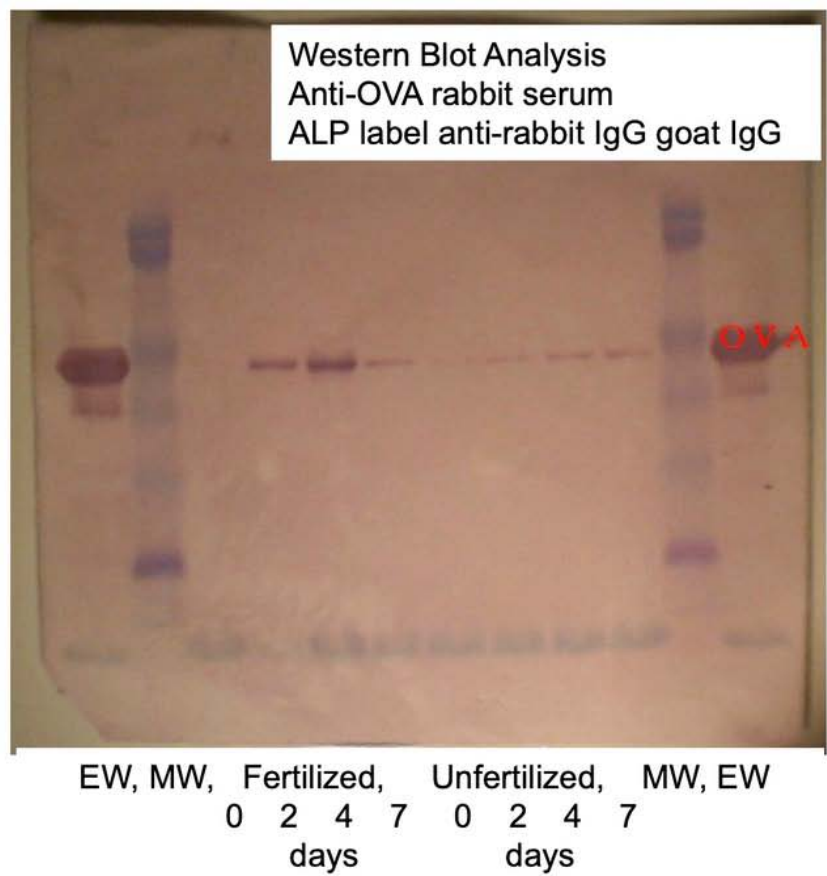

Figure 8. SDS-PAGE profile and Western blot analysis. EW; Egg White Liquid, MW: Molecular Weight Maker, Anti-OVA rabbit serum and ALP conjugated anti-rabbit IgG goat IgG was used to visualize OVA in egg yolk proteins. Pre-stained protein maker (Nacalai tesque Inc., Japan) was used: $\beta$-Galactosidase (MW 120 kDa), Bovine serum albumin (MW 98 kDa), Ovalbumin (MW 49 kDa). Carbonic anhydrase (MW 37.5 kDa), Myoglobin (MW 29.5 kDa), and Lysozyme (MW 20.5 kDa).

There was no change in the band of constituent proteins in the unfertilized egg yolk on SDS-PAGE. On the other hand, in the fertilized egg yolk, a band corresponding to the molecular weight of OVA was prominently observed in the yolk on day 4. After Western blotting, immunostaining was performed to detect OVA. OVA was not detected in the egg yolk of the fertilized egg on day 0 . However, OVA was detected in the egg yolk samples on days 2, 4, and 7. The color development intensity of immunostaining was stronger on day 4 than day 2 and weaker on day 7 . In addition, a slight immunostaining band of OVA was observed in the unfertilized egg yolk.

\section{Discussion}

\subsection{Quantitative and qualitative changes in egg constituents during incubation}

To elucidate the cooking principal of a reversed boiled egg, fertilized and unfertilized eggs were incubated for 7 days at $38^{\circ} \mathrm{C}$ with $\mathrm{RH} 70 \%$. The quantitative and qualitative changes of the egg yolk and egg white were compared. The composition ratio of chicken eggs (eggshell/yolk/egg white ratio) did not change in unfertilized eggs, but in fertilized eggs, the yolk doubled, and the egg white halved as the hatching process progressed. An embryo grew rapidly from day 3 (Figure 2). In the compositional analysis of fertilized eggs, the water content of the egg yolk increased sharply on day 3 , whereas the water content of the egg white decreased. The yolk $\mathrm{pH}$ increased about one unit, showing a neutral $\mathrm{pH}$. These dramatic changes were seen on days 2-3 when embryonic growth began. These changes may be the physiological phenomenon for embryonic development in a fertilized egg (Figures 3 and 4).

Regarding the egg white $\mathrm{pH}$, it is known that carbon dioxide is dissolved in a fresh egg white. Upon being laid, carbon dioxide is released from the egg white, and the egg white's $\mathrm{pH}$ rises to more than 10 [4]. The egg white $\mathrm{pH}$ of unfertilized eggs showed the same phenomenon as the $\mathrm{pH}$ change generally recognized in stored eggs [5]. Because it took 1-2 days to receive fertilized eggs from the farm in this study, the egg white $\mathrm{pH}$ in fertilized eggs exceeded 9 from day 0 , which is as same as the $\mathrm{pH}$ of unfertilized eggs at day 2. However, $\mathrm{pH}$ gradually decreased from 9.8 on days 2-3 to 8.6 on day 7. This may be because some metabolites lowered the egg white $\mathrm{pH}$ as the embryo grows [6]. 
These changes in weight, water content, and $\mathrm{pH}$ in the shelled egg mean that the water of the egg white or the egg white itself passed through the vitelline membrane. As a result, the yolk viscosity of fertilized eggs decreased dramatically from days 3-4 and became watery. On the other hand, the water content of egg white decreased from $90 \%$ to about $60 \%$, resulting in thicker egg white. The same phenomenon was observed by Ex Ovo Culture System [7]. Furthermore, by analyzing the SDS-PAGE and Western blotting profiles of the egg yolk in fertilized eggs, OVA was significantly detected by immunostaining from the watery egg yolk on day 2-7. Akizawa et al. has reported that OVA-related protein $\mathrm{X}$ (OVAX) was identified in the egg yolk of the ten days developing fertilized egg [8]. From the above results, it is suggested that the cause of increasing egg yolk ratio in fertilized eggs is that the water and proteins of the egg white pass through the vitelline membrane for starting the embryo growth. However, in this study, OVA was slightly detected even in the yolk of unfertilized eggs as reported by Gao et al. [9]. Therefore, more detailed research is needed in the future.

\subsection{Changes in the heat gelation of chicken egg components during incubation}

The dynamic viscoelasticity of the white and yolk of fertilized eggs during incubation was examined. Normally, in dynamic viscoelasticity measurement, the storage elastic modulus (G'), which indicates the elasticity of a substance, and the loss elastic modulus (G'), which indicates the viscosity, are measured. In this study, the temperature at which G' begins to rise is considered as the gelation starting point, and the temperature at which G' stops rising is considered as the gel hardening point [3].

In food science, it is commonly understood that egg white usually starts gelling at $60^{\circ} \mathrm{C}$ and the gel hardens at $80^{\circ} \mathrm{C}$, and the egg yolk starts gelling at $65^{\circ} \mathrm{C}$ and hardens at $75^{\circ} \mathrm{C}$ [10]. In this study, the egg yolk and egg white in unfertilized eggs showed similar values of starting and hardening points like a normal yolk and white. However, the gelation starting point and hardening point of an egg white stored for 7 days increased by about $5^{\circ} \mathrm{C}$ (Figures $6 \mathrm{a}$ and $6 \mathrm{~b}$ ). This is because OVA changed to a heat-stable S-OVA during storage. Generally, the heat denaturation temperature of OVA is about $78^{\circ} \mathrm{C}$, and S-OVA is about $87^{\circ} \mathrm{C}$ [11]. Our research group reported that the heating denaturation temperatures of native, intermediate, and heat-stable forms (S-OVA) of egg white in fertilized and unfertilized eggs measured by a differential scanning calorimeter are about $78^{\circ} \mathrm{C}, 82^{\circ} \mathrm{C}$, and $86^{\circ} \mathrm{C}$, respectively [1].

On the other hand, the initial gelation point and hardening point of the yolk of fertilized eggs shifted to the high temperature side by about $5^{\circ} \mathrm{C}$ on day 3 and about $10^{\circ} \mathrm{C}$ on day 4 and remained constant after that (Figures 7c and 7d). Therefore, as the embryonic growth progressed, the water content of the egg yolk increased, and it became difficult to gel. This study showed that in the preparation of a reversed boiled egg, the gelation starting temperature of the yolk was $65^{\circ} \mathrm{C}$ and the gel hardening temperature was $70^{\circ} \mathrm{C}$. Regarding the egg white in fertilized eggs, OVA, a major protein in egg white, is converted into a heat-stable S-OVA. However, the rising starting point of G' of the egg white on day 7 shifted to a lower temperature, meaning that the egg white tends to be gelled easily as the embryonic growth progressed. This may be because the fertilized egg white sample on day 7 could recover only thick egg white. Furthermore, the protein concentration of the egg white increased from $10 \%$ to $25 \%$ because the water in the egg white was transferred to the egg yolk.

\subsection{Preparation principal of a reversed boiled egg}

A reversed boiled egg could be reproduced from a fertilized egg that had been incubated for 3-4 days under hatching conditions $\left(38^{\circ} \mathrm{C}, \mathrm{RH} 70 \%\right)$ (Figure 6). As for why the reversal of egg yolk and egg white occurs, the dramatic decrease in the egg yolk viscosity (water-like egg yolk) seems to be most related to the condition of cooking a reversed boiled egg. As a change associated with the incubation of fertilized eggs, the yolk viscosity decreased to 50cp on day 3 and decreased to $10 \mathrm{cp}$ or less on day 4 , which is as same viscosity as water. With this change, the dense viscosity of the egg yolk disappeared, resulting from watery egg yolk. When a needle is stabbed in eggs, the egg yolk in unfertilized eggs cannot be spread because of the high viscosity of the egg yolk. On the other hand, the egg yolk in fertilized eggs has almost no viscosity. Therefore, the watery egg yolk is dispersed outward in the eggshell. Accordingly, the egg white has a high viscosity because the egg white provides water and proteins to the egg yolk, remains inside. This process results in a reversed boiled egg.

\section{Conclusion}

When the fertilized egg was incubated under hatching conditions, the yolk and egg white were reversed from day 3 to day 4, and a reversed boiled egg was recreated for the first time in 220 years. The reason why the egg yolk and egg white reversal occurs involves the dramatic changes in the fertilized egg on days 3-4 during the hatching condition. A significant amount of water in the egg white has penetrated the yolk through the vitelline membrane, and the yolk weight is about doubled, and the egg white weight is halved. Due to this phenomenon, the yolk viscosity drops from $1,250 \mathrm{cp}$ to $10 \mathrm{cp}$ or less. The particular dense yolk viscosity disappears, becoming watery. The vitelline membrane 
becomes fragile, and it is possible to break it without cracking the eggshell just by rotating the egg softly while boiling. This principle of recreating a reversed boiled egg was depicted in Figure 9.

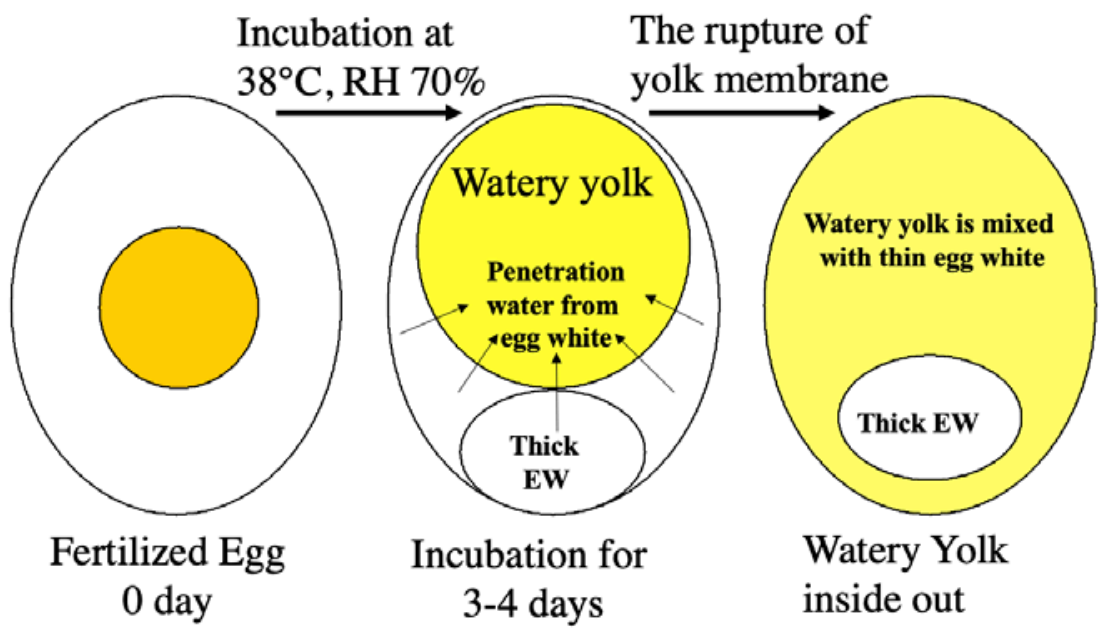

Figure 9. Preparation principal of a reversed boiled egg before being boiled.

In the late Edo period (1781-1868), "Fresh eggs" were mainly fertilized eggs. Fertilized eggs incubated for 3-4 days may have been sold throughout Edo (the former name of Tokyo) city. In the Edo period, egg sellers put eggs in baskets and carried them while balancing them with a balancing pole (Furi-Uri in Japanese). The impact during transportation did not break the eggshell, but the weakened vitelline membrane broke. Accordingly, it is imagined that the egg yolk diffuses to the outside, and the thickened egg white remains inside.

Additionally, when the operation of "making a hole toward the head with a needle" is performed as described in the old cookbook, the yolk diffuses outward because the water-like yolk has almost no viscosity. The thickened egg white has a gel-like structure and does not mix with the water-like egg yolk. When such an egg is boiled and stirred slowly, the watery egg yolk diffused to the outside begins to gel at around $75^{\circ} \mathrm{C}$ and coagulates around $85^{\circ} \mathrm{C}$. Finally, the thick egg white located at the center of the egg is coagulated, resulting in a reversed boiled egg.

\section{Conflicts of Interest}

The authors declare no conflict of interest.

\section{Funding Statement}

This research received no external funding.

\section{Acknowledgments}

We want to thank the late Shigemitsu Akachi, Ph.D., for supervising us to complete this research. We also like to thank Professor Yasuki Matsumura for his advice on analyzing the dynamic viscoelasticity data of the egg yolk and egg white.

\section{References}

[1] Hatta, H., Nomura, M., Takahashi, N., and Hirose, M. (2001). Thermostabilization of Ovalbumin in a Developing Egg by an Alkalinity-regulated, Two-step Process: Bioscience, Biotechnology, and Biochemistry, 65, 2021-2027.

[2] Laemmli, U. K. (1970). Cleavage of structural proteins during the assembly of the head of bacteriophage T4: Nature, 227: 680-685.

[3] Matsumura, Y. and Mori, T. (1996). 4 Gelation in Methods of Testing Protein Functionality, G. M. Hall (Eds.), Blackie Academic \& Professional, pp. 76-109.

[4] Caner, C. and Yuceer, M. (2015). Efficacy of various protein-based coating on enhancing the shelf life of fresh eggs during storage: Poultry Science, 94: 1665-1677.

[5] Zang, Y. T., Bing, S. H., Li, Y. J., Shu, D. Q., Huang, A. M., Wu, H. X. Lan, L. T., and Wu, H. D. (2019). Efficacy of slightly acidic electrolyzed water on the microbial safety and shelf life of shelled eggs: Poultry Science, 98: 5932-5939

[6] Gul, H., Chen, X., and Geng, Z. (2021). Comparative Yolk Proteomic Analysis of Fertilized Low and High Cholesterol Eggs 
during Embryonic Development: Animals, 11, 744.

[7] Tahara, Y. and Obara, K. (2021). Ex Ovo Culture System for Avian Embryos and its Application: J. Poult. Sci., 58: 1-4.

[8] Akazawa, T., Ogawa, M., and Hayakawa, S. (2019). Migration of chicken egg-white protein ovalbumin-related protein X and its alteration in heparin-binding affinity during embryogenesis of fertilized egg: Poultry Science, 98: 5100-5108.

[9] Gao, D., Qiu, N., Liu, Y., and Ma, M. (2017). Comparative proteome analysis of egg yolk plasma proteins during storage: J. Sci. Food Agric., 97: 2392-2400.

[10] Hatta, H., Hagi, T., and Hirano, K. (1997). Chemical and physicochemical properties of hen eggs and their application in foods, in Hen eggs; Their basic and applied science, Yamamoto, T., Juneja, L. R., Hatta, H. and Kim, M. (Eds.), CRC Press, pp. 117-133.

[11] Donovan, J. W. and Mapes, C. J. (1975). A differential scanning calorimetric study of conversion of ovalbumin to S-ovalbumin in eggs. J. Sci. Food Agric., 27, 197-204. 